\title{
Relationship of Physical Status and Quality of Life in Stroke Survivors
}

\author{
Mandeep Kang and Navkaran.S.Shergill
}

\begin{abstract}
Aim: The purpose of this study was to examine the relationship between physical status and quality of life in stroke survivors. Material and Method: Participants for this study were 50 stroke survivors belonging to Amritsar district. 22 males and 28 females were recruited for this study. The patients are categorized into three categories: mild, moderate and severe according to their level of severity. Various standardized tools used to measure the physical disability in stroke survivors were: Functional independence measure (FIM), Structured questionnaire and WHO disability schedule. Quality of life was assessed using Stroke-specific quality of life (SS-QOL). The mean scores were calculated and correlation between physical status and quality of life in the three categories of stroke survivors were calculated using Pearson's correlation method. The correlation of musculoskeletal deformities, physical disability, degree of dependency and functional abilities with quality of life was calculated. Results: The results of the study depicted that quality of life in mild group of patients demonstrated a significant relationship with dependency in females and rural patients $(r=0.723$ and $r=0.679$ respectively, $d f=16, p<0.01)$ and in males $(r=0.474$, $\mathrm{df}=16, \mathrm{p}<0.05)$ and with functional abilities in males, females and rural patients $(\mathrm{r}=0.526$, $\mathrm{r}=0.483$ and $\mathrm{r}=0.581$ respectively, $\mathrm{df}=16, \mathrm{p}<0.05)$. The moderate group also observed a significant relationship with physical disability and dependency in total groups $(r=0.590$ and $\mathrm{r}=0.498, \mathrm{p}<0.01$ and $\mathrm{p}<0.05$ respectively). Whereas in severe group, a significant relationship existed with musculo-skeletal deformities, physical disability, dependency and functional abilities( $\mathrm{r}=0.580, \mathrm{r}=0.675, \mathrm{r}=0.664$ and $\mathrm{r}=0.584, \mathrm{p}<0.05$ respectively). Conclusion: The conclusions drawn from the study predict that quality of life is more impaired in severe group of patients as compared to mild and moderate. There is a significant relationship between quality of life and physical status in terms of physical disability, dependency and impairment in functional activities in the severe group, whereas in moderate group, a significant relationship is observed between quality of life and 2 domains of physical status, i.e., physical disability and dependency. On the other hand, the quality of life is not significantly impaired in the mild group. The results predict that females have poorer quality of life post-stroke as compared to males. Similarly, quality of life in rural patients is more affected compared to urban patients suffering from stroke.
\end{abstract}

\author{
Mandeep Kang \\ Research Scholar \\ Department of Physiotherapy \\ RIMT University, Mandi Gobindgarh, (Punjab) India \\ E-mail: dr.manikangz@gmail.com \\ Navkaran.S.Shergill \\ Assistant Professor \\ Department of Physiotherapy \\ RIMT University, Mandi Gobindgarh, (Punjab) India \\ E-mail: navkaran9999@gmail.com
}

Key Words: Cerebrovascular accident, physical status, disability, functional status, musculoskeletal deformities, dependency, quality of life

DOI: 10.18376/jesp/2021/v17/i1/163785 


\section{Journal of Exercise Science \& Physiotherapy Vol.17 No.1 (January to June) 2021 \\ ISSN: 0973-2020 (Print) I2OR Impact Factor =7.005 ISSN: 2454-6089 (Online)}

\section{Introduction}

A stroke is a sudden interruption in the blood supply of the brain. Most strokes are caused by an abrupt blockage of arteries leading to the brain (ischemic stroke). Other strokes are caused by bleeding into brain tissue when a blood vessel bursts (hemorrhagic stroke). Stroke is the second leading cause of death after ischemic heart disease and is characterized by high levels of disability among survivors. Stroke is one of the leading causes of death and disability in India. The estimated prevalence rate of stroke ranges, 84-262/100,000 in rural and 334-424/100,000 in urban areas. The incidence rate is $119-145 / 100,000$ based on the recent population based studies (Jeyaraj et al., 2013). Patients with stroke experience physical, psychological, social and economic burdens, and health related quality of life (QOL) of these patients are low. Most studies have shown that the quality of life in stroke patients were decreased (Shan et al., 2015 ; Tessa et al, 2015; Pulman and Buckley 2013). In addition to being a sudden event, stroke affects both the individual and family, and as a result a high number of stroke patients are unable to work and receive financial assistance after stroke (Szymon et al., 2020). Quality of life was defined by the World Health Organization (WHO) as 'An individual's perception of their position in life in the context of the culture and value systems in which they live and in relation to their goals, expectations, standards and concerns.' Stroke has multitude of negative consequences on an individual's life ranging from institutionalization, and loss of independence to cognitive and communication difficulties, thus causing a detrimental effect, both on short term and/or long term quality of life (Babith et al., 2019). The present study focuses on observing the relationship of the physical status in mild, moderate and severe stroke survivors in terms of musculoskeletal deformities, dependency, disability and impairment in functional activities with the quality of life of stroke survivors. It explores the influence of gender (male, female) and geographical area (rural, urban) on the physical status and quality of life of stroke survivors. Few studies suggest that women are significantly more disabled after stroke in dressing, grooming and transfers (Rodica et al., 2009). Post-stroke women are more disabled as compared to men due to their weak emotional stability and psychological status (SueMin et al., 2005). Following rehabilitation, a large proportion of patients recovered from severe dependency on basic daily activities. The improvement is more pronounced among patients with less severe stroke than those who are more severe (Manuel and Mercedes 2020).

\section{Materials and Method}

The sample was collected through survey type of research. A random sample of 50 post-stroke patients (both male and female, rural and urban) were chosen for this study. The scales were administered to the stroke patients belonging to Amritsar district. The sample chosen was assessed for physical status and quality of life. The physical status was assessed in terms of disability, degree of dependency, musculoskeletal deformities and functional abilities. The patients were categorized into three categories: mild, moderate and severe according to the level of severity. The standardized tools used for the physical status and quality of life assessment of the stroke survivors were:

- Functional Independence measure

- Structured questionnaire

- Disability assessment schedule (WHO)

- Stroke-specific quality of life(SS-QOL)

In order to find out the relationship between the physical status and quality of life of stroke survivors, the mean scores were calculated. The Pearson's coefficient of correlation was calculated to find out the relationship between physical status and quality of life in stroke survivors. 


\section{Results}

Table1. Relationship of the physical status with quality of life in the mild group

\begin{tabular}{|c|c|c|c|c|c|}
\hline \multirow{7}{*}{$\begin{array}{l}\text { Quality } \\
\text { of life }\end{array}$} & \multicolumn{5}{|c|}{ Physical Status } \\
\hline & & $\begin{array}{l}\text { Musculo- } \\
\text { skeletal } \\
\text { Deformities }\end{array}$ & $\begin{array}{l}\text { Physical } \\
\text { Disability }\end{array}$ & $\begin{array}{l}\text { Degree of } \\
\text { Dependency }\end{array}$ & $\begin{array}{l}\text { Impaired } \\
\text { Functional } \\
\text { Abilities }\end{array}$ \\
\hline & $\begin{array}{l}\text { Total } \\
\text { group }\end{array}$ & 0.311 & 0.412 & 0.442 & 0.452 \\
\hline & Male & 0.274 & 0.345 & $0.474 *$ & $0.526^{*}$ \\
\hline & Female & 0.121 & $0.542 *$ & $0.723 * *$ & $0.483^{*}$ \\
\hline & Rural & 0.035 & 0.456 & $0.679 * *$ & $0.581 *$ \\
\hline & Urban & 0.345 & 0.392 & 0.450 & 0.370 \\
\hline
\end{tabular}

Table 1 shows that the physical disability is significantly related to quality of life in females $(\mathrm{r}=0.542, \mathrm{df}=16, \mathrm{p}<0.05)$. On studying the relationship of dependency in mild group with quality of life, it was observed that dependency is significantly related to quality of life in females and rural patients $(r=0.723$ and $r=0.679$ respectively, $d f=16, p<0.01)$ and in males $(r=0.474, d f=16, p<0.05)$. The mild group was evaluated to find out the relationship of quality of life with functional abilities. The relationship of quality of life and functional abilities is significant in males, females and rural patients $(r=0.526, r=0.483$ and $r=0.581$ respectively, df $=16, p<0.05)$. Whereas there is no significant relationship observed between quality of life and musculoskeletal deformities in mild group.

Table 2. Relationship of the physical status with quality of life in the moderate group

\begin{tabular}{|l|l|l|l|l|l|}
\hline & \multicolumn{5}{|c|}{ Physical status } \\
\hline \multirow{4}{*}{$\begin{array}{l}\text { Quality } \\
\text { of life }\end{array}$} & $\begin{array}{l}\text { Musculo- } \\
\text { skeletal } \\
\text { Deformities }\end{array}$ & $\begin{array}{l}\text { Physical } \\
\text { Disability }\end{array}$ & $\begin{array}{l}\text { Degree of } \\
\text { Dependency }\end{array}$ & $\begin{array}{l}\text { Impaired } \\
\text { Functional } \\
\text { Abilities }\end{array}$ \\
\cline { 2 - 6 } & $\begin{array}{l}\text { Total } \\
\text { group }\end{array}$ & 0.345 & $0.590^{* *}$ & $0.498^{*}$ & 0.417 \\
\cline { 2 - 6 } & Male & 0.256 & $0.541^{*}$ & $0.536^{*}$ & $0.499^{*}$ \\
\cline { 2 - 6 } & Female & 0.298 & $0.675^{* *}$ & $0.690^{* *}$ & $0.677^{* *}$ \\
\cline { 2 - 6 } & Rural & $0.527 *$ & $0.824^{* *}$ & $0.895^{* *}$ & $0.532^{*}$ \\
\cline { 2 - 6 } & Urban & 0.424 & $0.560^{*}$ & $0.504^{*}$ & $0.571^{*}$ \\
\hline
\end{tabular}

Table 2 shows that a significant relationship exists between quality of life and physical status in moderate group. The results revealed that physical disability in total group, females and rural patients was significant $(r=0.590, r=0.675$ and $r=0.824$ respectively, $d f=17, p<0.01)$ and in males and urban population $(\mathrm{r}=0.541$ and $\mathrm{r}=0.560$ respectively, $\mathrm{df}=17, \mathrm{p}<0.05)$.

On examining the relationship of quality of life with dependency in moderate group, it is observed that dependency is significantly correlated with quality of life in total group, males and urban 
patients $(r=0.498, r=0.536$ and $r=0.504$ respectively, $\mathrm{df}=17, \mathrm{p}<0.05$, respectively) and in females and rural patients $(\mathrm{r}=0.690$ and $\mathrm{r}=0.895$ respectively, $\mathrm{df}=17, \mathrm{p}<0.01)$.

The moderate group has a significant relationship between quality of life and functional abilities. The relationship of quality of life with functional abilities is significant in males, rural and urban population $(r=0.499, r=0.532$ and $r=0.571$, respectively, $d f=17, p<0.05)$ and in females $(r=0.677$, $\mathrm{df}=17, \mathrm{p}<0.01$ ). Whereas, a significant relationship was observed in quality of life and musculoskeletal deformities in the rural patients $(\mathrm{r}=0.527, \mathrm{df}=17, \mathrm{p}<0.05)$.

Table 3.Relationship of the physical status with quality of life in severe group

\begin{tabular}{|c|c|c|c|c|c|}
\hline & \multicolumn{5}{|c|}{ Physical status } \\
\hline \multirow{6}{*}{$\begin{array}{l}\text { Quality } \\
\text { of life }\end{array}$} & & $\begin{array}{l}\text { Musculo- } \\
\text { skeletal } \\
\text { Deformities }\end{array}$ & $\begin{array}{l}\text { Physical } \\
\text { Disability }\end{array}$ & $\begin{array}{l}\text { Degree of } \\
\text { Dependency }\end{array}$ & $\begin{array}{l}\text { Impaired } \\
\text { Functional } \\
\text { Abilities }\end{array}$ \\
\hline & $\begin{array}{l}\text { Total } \\
\text { group }\end{array}$ & $0.580 *$ & $0.675^{*}$ & $0.664 *$ & $0.584 *$ \\
\hline & Male & $0.648 *$ & $0.613 *$ & $0.583^{*}$ & $0.607 *$ \\
\hline & Female & $0.689 * *$ & $0.716 * *$ & $0.790 * *$ & $0.815 * *$ \\
\hline & Rural & $0.675^{*}$ & $0.810 * *$ & $0.789 * *$ & $0.621 *$ \\
\hline & Urban & $0.677^{*}$ & $0.795 * *$ & $0.593 *$ & $0.639 *$ \\
\hline
\end{tabular}

Table 3 shows that patients of severe group had a significant relationship between quality of life and physical status of stroke survivors. The table depicts that musculoskeletal deformities have a significant relationship with quality of life in female patients $(r=0.689, \mathrm{df}=11, \mathrm{p}<0.01)$ and in total group, male, rural and urban patients $(r=0.580, r=0.648, r=0.675$ and $r=0.677$ respectively, $\mathrm{df}=11$, $\mathrm{p}<0.05)$. On examining the relationship between quality of life and physical disability in severe group, it is found that the relationship was significant for the total group and male patients $(r=0.675$ and $\mathrm{r}=0.613$ respectively, $\mathrm{df}=11, \mathrm{p}<0.05)$ and in females, rural and urban patients $(\mathrm{r}=0.716, \mathrm{r}=0.810$ and $\mathrm{r}=0.795$ respectively, $\mathrm{df}=11, \mathrm{p}<0.01$ ).

In addition, the results of this table indicate a significant relationship of quality of life and dependency in total group, male and urban patients $(r=0.664, r=0.583$ and $r=0.593$ respectively, $\mathrm{df}=11, \mathrm{p}<0.05)$ and in females and rural patients $(\mathrm{r}=0.790$ and $\mathrm{r}=0.789$ respectively, $\mathrm{df}=11, \mathrm{p}<0.01)$ in severe group. The relationship of quality of life and functional abilities in the severe group of stroke survivors is significant in total group, male, rural and urban patients $(r=0.584, r=0.607$, $\mathrm{r}=0.621$ and $\mathrm{r}=0.639$ respectively, $\mathrm{df}=11, \mathrm{p}<0.05)$ and in females patients $(\mathrm{r}=0.815$ respectively, $\mathrm{df}=11, \mathrm{p}<0.01$ ).

The results of the study shows that severe group has poorer quality of life as compared to mild and moderate. It is observed that females have poorer quality of life as compared to males. Similarly, quality of life in rural patients is more affected compared to urban patients.

\section{Discussion}

The relationship of dependency in mild group with quality of life was observed to be significant in males, females and urban patients. The relationship of quality of life and functional abilities was found to be significant in males, females and urban patients. These results are consistent with the findings of another study suggesting a positive and significant correlation between scores on the Perceived Social Support from the Family Scale and various aspects of quality of life, such as functional status (Nuray and Mehtap 2010). On the other hand, physical disability was significantly 


\section{Journal of Exercise Science \& Physiotherapy Vol.17 No.1 (January to June) 2021 \\ ISSN: 0973-2020 (Print) I2OR Impact Factor =7.005 ISSN: 2454-6089 (Online)}

correlated only in females. Whereas, no significant relationship was observed between quality of life and musculo-skeletal deformities in mild group. In the moderate group, the physical disability, dependency and functional abilities was correlated to quality of life in total group, males, females, rural and urban patients. These results are in consonance with the findings of Marwa et al., (2017) suggesting a significant positive relationship was found between the functional abilities of the stroke patients and their quality of life. Whereas in musculo-skeletal deformities, the correlation was significant only in rural patients. Whereas, in the severe group of stroke survivors the quality of life was significantly correlated to musculo-skeletal deformities, physical disability, dependency and functional abilities in the total group. Thus, the stroke severity is a robust factor in predicting quality of life in patients with stroke, particularly in physical domains (Chien-Min et al., 2015). It is observed that females have poorer quality of life as compared to males. Female sex is associated with poorer functional outcome after acute ischemic stroke. Women are more likely to be severely disabled (Susan 2019; Christine and Louise 2008; Juliaet al., 2007). Women are also more likely than men to report and experience depression after stroke (Eriksson et al., 2004; Everson et al., 1998 and House et al., 2001). This possibly makes recovery from stroke more difficult, thus leading to poor quality of life in women (Herrmann et al., 1998 ; Parikh et al., 1990). In the present study, demographic status of stroke survivors i.e., rural or urban was found to influence their quality of life. Patients in rural areas were found to have a lower quality of life than patients in urban areas. There are a number of possible reasons for this. Firstly, housing and economic conditions between urban and rural areas differ. Secondly, the two areas have different health issues as a result of the different services provided and for geographic reasons (Son 2005). People living in rural areas might form looser bonds with family due to limited transportation and travel difficulties. Therefore, the loneliness and deprivation of treatment, medication and rehabilitation services results in a poorer quality of life in patients residing in rural areas compared to those residing in urban areas.

\section{Conclusion}

The conclusions drawn from the study predict that quality of life is more impaired in severe group of patients as compared to mild and moderate. There is a significant relationship between quality of life and physical status in terms of physical disability, dependency and impairment in functional activities in the severe group, whereas in moderate group, a significant relationship is observed between quality of life and 2 domains of physical status, i.e., physical disability and dependency. On the other hand, the quality of life is not significantly impaired in the mild group. The results predict that females have poorer quality of life post-stroke as compared to males. Similarly, quality of life in rural patients is more affected compared to urban patients suffering from stroke.

\section{References}

Babitha Rajan, S. Pruthvish, K. Lalitha, Murali Tyloth and N. S. Murthy.2019. Assessment of quality of life among stroke survivors: a longitudinal study. International Journal of Community Medicine and Public Health. 2019 Mar; 6(3):1316-1323.

Chien-Min Chen, Chih-Chien Tsai, Chia-Ying Chung, Chia-Ling Chen, Katie PH Wu and Hsieh-Ching Chen .2015. Potential predictors for health-related quality of life in stroke patients undergoing inpatient rehabilitation. Health and Quality of Life Outcomes volume 13, Article number: 118 .

Christine L. Turtzo and Louise D. McCullough.2008.Sex Differences in Stroke. Cerebrovasc Dis. 2008 Nov; 26(5): 462-474.

Eriksson. M., Asplund. K., Glader. E.L., Norrving. B., Stegmayr. B., Terent. A., Asberg. K.H. and Wester. P.O.2004.Self-reported depression and use of antidepressants after stroke: a national survey. Stroke. 2004;35:936-941.

Everson. S.A., Roberts. R.E., Goldberg. D.E. and Kaplan. G.A.1998. Depressive symptoms and increased risk of stroke mortality over a 29-year period. Arch Intern Med. 1998;158:1133-1138.

Herrmann. N., Black. S.E., Lawrence. J., Szekely. C. and Szalai. J.P.1998. The Sunnybrook Stroke Study: a prospective study of depressive symptoms and functional outcome. Stroke. 1998;29:618-624. 


\section{Journal of Exercise Science \& Physiotherapy Vol.17 No.1 (January to June) 2021 ISSN: 0973-2020 (Print) I2OR Impact Factor = 7.005 ISSN: 2454-6089 (Online)}

House. A., Knapp. P., Bamford. J. and Vail. A.2001. Mortality at 12 and 24 months after stroke may be associated with depressive symptoms at 1 month. Stroke. 2001;32:696-701.

Jeyaraj Durai Pandian and Paulin Sudhan.2013. Stroke Epidemiology and Stroke Care Services in India. Journal of Stroke 2013; 15(3):128-134.

Julia Warner Gargano and Mathew. J. Reeves.2007. Sex Differences in Stroke Recovery and Stroke-Specific Quality of Life. Stroke. 2007; 38: 2541-2548.

Manuel Murie-Fernández and Mercedes Molleda Marzo 2020. Predictors of Neurological and Functional Recovery in Patients with Moderate to Severe Ischemic Stroke: The EPICA Study. Stroke Res Treat. May 2020.

Marwa Amin Abd Allah, Ikbal Fathalla El-Shafie and Fatma El-Sayed Soliman. 2017. Effect of Functional Ability on Quality of Life among Diabetic Elderly in Basion City. International Journal of Novel Research in Healthcare and Nursing Vol. 4, Issue 3, pp: (64-79), Month: September - December 2017.

Nuray Dayapoglu and Mehtap Tan.2010.Quality of life in stroke patients. Neurology India. Volume : 58, Issue : 5, Page : 697-701.

Parikh. R.M., Robinson. R.G., Lipsey. J.R., Starkstein. S.E., Fedoroff. J.P .and Price. T.R.1990. The impact of post-stroke depression on recovery in activities of daily living over a 2-year follow-up. Arch Neurol. 1990; 47:785-789.

Pulman. J. and Buckley. E.2013. Assessing the efficacy of different upper limb hemiparesis interventions on improving health-related quality of life in stroke patients: a systematic review. Top Stroke Rehabil.2013;20:171-88.

Rodica. E. Petrea, Alexa. S. Beiser, Sudha Seshadri, Margaret Kelly-Hayes, Carlos S. Kase and Philip A. Wolf 2009. Stroke in women - Gender Differences in Stroke Incidence and Post-stroke Disability in the Framingham Heart Study. Stroke. 2009; 40:1032-1037.

Shan. L., Shan. J., Saxena. A. and Robinson. D.2015. Quality of life and functional status after carotid revascularisation: a systematic review and meta-analysis. Eur J Vasc Endovasc Surg 2015;49:63445.

Son. S.R.2005. A comparative study on the life quality of the elderly in urban and rural areas. Master's thesis, Graduate School of Honam University, 2005, p 6.

Sue-Min Lai, Pamela. W. Duncan, Paul Dew and John Keighley.2005. Sex Differences in Stroke Recovery. Preventing Chronic Disease.2005 July. Vol.2. No.3.A13.page 1-11.

Susan Fitzgerald.2019. In Stroke, Outcomes Differ for Men and Women. Centre for Women's health research. University of Colorado Anschutz Medical Campus.

Szymon Jarosławski , Bożena Jarosławska , Barbara Błaszczyk , Pascal Auqier and Mondher Toumi.2020. Health-related quality of life of patients after ischaemic stroke treated in a provincial hospital in Poland. Journal of Market Access and Health Policy.2020, VOL. 8, 1775933.

Tessa van Middelaar, Edo Richard, H. Bart van der Worp, Pepijn van den Munckhof, Pythia. T. Nieuwkerk, Marieke. C. Visser, Jan Stam, and Paul. J. Nederkoorn.2015. Quality of life after surgical decompression for space-occupying middle cerebral artery infarction: systematic review. Int $J$ Stroke 2015;10:170-6.

Conflict of Interest: None declared 